\title{
FAMÍLIA E MUSEU DE ARTE: A ACESSIBILIDADE DE PESSOAS COM DEFICIÊNCIA NOS ESPAÇOS EXPOSITIVOS
}

\author{
Priscila Anversa
}

\begin{abstract}
Resumo
O presente artigo aborda os temas Família e Inclusão, discutindo aspectos sobre a acessibilidade nos espaços expositivos e culturais. O texto apresenta reflexões sobre a importância da efetivação de programas que integrem as pessoas com deficiência, a família e o museu. O diálogo é norteado pela pesquisa realizada no curso de Pós-Graduação em Artes Visuais, concluído em 2011, a qual levantou dados acerca do que pensam as famílias sobre a formação artística dos filhos com deficiência. Destaca-se a questão da acessibilidade nos museus e espaços expositivos em Florianópolis, partindo da fala das mães entrevistadas. Apresentam-se possibilidades de aproximar a família das instituições culturais, problematizando esse campo não formal de educação, além de debates que permeiam a herança cultural e a mediação educativa.
\end{abstract}

Palavras-chave: família; acessibilidade; inclusão; espaços expositivos; museu

\begin{abstract}
This paper approach the topics Family and Inclusion, discussing aspects of accessibility in the cultural and exhibition spaces. The text presents reflections on the importance of effective programs that integrates people with disabilities, the family and the museum. The dialogue is guided by research conducted in Masters Degree of Visual Arts, completed in 2011, wich explored data about what the families think about the artistic formation of children with disabilities. There is the issue of accessibility in museums and exhibition spaces in Florianópolis, from the speech of the mothers interviewed. It shows possibilities to approximate family of cultural institutions, questing non-formal education field, as well as debates that permeate the cultural heritage and educative mediation.
\end{abstract}

Key-words: family; accessibility; inclusion; exhibition space; museum

\section{Introdução}


Buscar entender o que inviabiliza a mobilização de famílias que têm filhos com deficiência a espaços culturais foi uma das questões que motivaram a pesquisa para o mestrado em Artes Visuais. A premissa inicial de que essas famílias têm acesso bastante restrito aos bens culturais foi crucial para entender o que as faz deixar de ir a uma exposição de arte e dar preferência a roteiros focados em comércio ou outro tipo de lazer. Certamente, existem inúmeras circunstâncias que tornam um menos atrativo do que o outro. Mas a proposta deste artigo não é entrar neste questionamento, e sim dialogar sobre o que de fato se observou que afastou (e muito), as famílias dos espaços expositivos e culturais.

A acessibilidade foi o ponto em comum que prevaleceu na fala das cinco famílias que participaram da pesquisa. As mães foram entrevistadas através de um gravador digital de áudio, que gerou um diálogo acerca dos mecanismos que elas utilizavam para construir a formação artística do filho com deficiência. A proposta foi perceber a fala dessas famílias: o que pensam e o que dizem a respeito da arte, do ensino de Arte, da frequência que vão aos espaços destinados à arte e cultura e à importância que dão a essas atitudes.

O último ponto acima citado deu vida a este artigo, porque trouxe questionamentos e reflexões sobre acessibilidade às pessoas com deficiência nos espaços culturais. Para remontar a pesquisa, o artigo discutirá a questão da inclusão das pessoas com deficiência do âmbito social e escolar, abordará também o tema família, enredando as falas das mães entrevistadas e suas relações com museu, espaços expositivos e acessibilidade.

\section{O espaço da Inclusão nos museus de Arte}

Os museus são locais onde se criam e se recriam experiências. Potencializam e socializam o conhecimento, a fim de promover visões de mundo e estimular a criticidade dos indivíduos e grupos que os frequentam. São territórios de aprendizagem e, portanto, espaços de encontro para a elaboração coletiva de sentidos. Por ser o museu um lugar que propõe experiências entre público-obramediador visando o saber, é correto afirmar que essa vivência precisa ocorrer em qualquer esfera, sobretudo, a qualquer público. No que diz respeito às pessoas com deficiência, o processo de ensino e aprendizagem coletivo é também articulado e 
potencializado numa mediação, visto que elas precisam de variados recursos para a efetivação da produção de conhecimento numa experiência desse âmbito.

O mediador buscará tocar o repertório do espectador, produzindo sentidos e criando significados. Dewey (1974) aponta para os três eixos que podem ser atingidos pela obra de arte em uma mediação: o intelectual, o prático e o emocional. Partindo desses princípios, é importante lembrar que pessoas com deficiência necessitam mediações diferenciadas, inclusive para se atingir de forma completa a sensibilização diante de uma obra, e consequentemente, desencadearem os processos citados pelo autor.

Cada vez mais esse público tem tido oportunidades de vivenciar experiências em espaços expositivos, com o incentivo e a criação de programas. Durante muitos anos parte do público de pessoas com deficiência continuou na inércia, ausente da instituição por não reconhecer sua identidade dentro daquilo que era exposto nestes espaços. A partir do momento que se valorizou novas linhas de produção artística - e estas foram incorporadas às curadorias -, este público, antes "excluído", passou com maior frequência a visitar os museus e estar em contato com a arte.

Ainda assim, atualmente a arte institucionalizada não é acessível a todos, e as pessoas com deficiência estão, de modo geral, afastadas do acesso às artes. A inacessibilidade se manifesta de duas maneiras: pelas dificuldades que os não iniciados no mundo da arte têm, que é o afastamento dos que não foram alfabetizados na estética institucionalizada, e também pelo fato de as instituições culturais não disporem de programas de adaptação dos objetos artísticos e de outros recursos necessários para a viabilização da inclusão de pessoas com deficiência em espaços expositivos.

Um dos aspectos importantes na definição de uma política de acessibilidade diz respeito às escolhas de exposições. Dentro de uma proposição integrada com diversas necessidades, o espaço museológico deve poder contar com a participação de artistas que busquem um sentido interativo de fato com o objeto artístico.

Atender o público de pessoas com deficiência depende de mudanças culturais e institucionais. As leis que garantem a acessibilidade de todos à educação já existem, e se na linguagem artística esse acesso requer visita a museus é a instituição que deve se adequar. Os ajustes devem ser compreendidos pelas diferentes áreas que 
atuam no museu como conservação, curadoria, pesquisa, ação educativa, adaptação de materiais etc.

\begin{abstract}
A fim de possibilitar às pessoas com deficiência viver de forma independente e participar plenamente de todos os aspectos da vida, os Estados Partes tomarão as medidas apropriadas para assegurar às pessoas com deficiência o acesso, em igualdade de oportunidades com as demais pessoas, ao meio físico, ao transporte, à informação e comunicação, inclusive aos sistemas e tecnologias da informação e comunicação, bem como a outros serviços e instalações abertos ao público ou de uso público, tanto na zona urbana como na rural. (CONVENÇÃO..., 2007, p. 22).
\end{abstract}

O desenvolvimento de alternativas para subsidiar a acessibilidade consiste um grande desafio aos pesquisadores, que buscam meios para facilitar a acessibilidade para a inclusão de pessoas com deficiência em espaços expositivos. As especificidades de cada deficiência envolvem questões singulares ao desenvolvimento de projetos, e desencadeiam consequentemente um processo rico de ensino e de aprendizagem para espectador e educador.

Em Florianópolis, alguns projetos vêm sendo realizados para instigar a visitação de pessoas com deficiência a museus e espaços expositivos, como exposições para tocar, voltadas ao público cego, e, recentemente, um projeto voltado especificamente para famílias com filhos com deficiência, inspirado em programas semelhantes desenvolvidos em países europeus. O projeto "Família no Museu: Um Encontro Inclusivo" destinou-se às famílias que possuíam em seu meio pessoas com deficiência, interessadas em participar de ações voltadas à inclusão e acessibilidade através da arte, cultura e lazer, buscando aproximar a família e o museu. A ação, realizada no Museu Histórico de Santa Catarina - Palácio Cruz e Sousa, procurou desenvolver mecanismos que estimulassem a participação das famílias aos espaços dedicados à arte e cultura, consistindo um projeto piloto para analisar as possibilidades da inserção de um programa permanente.

Levou-se em conta a relevância em aproximar as famílias que tivessem filhos com deficiência ao Museu, para que visitassem exposições de arte, ampliando a acessibilidade deste público a espaços expositivos. Vislumbrou-se, também, a ampliação de oportunidades de apreciação estética e contato com arte, para instigá- 
los a retornarem ao Museu, considerando a debilidade em espaços expositivos inclusivos na cidade de Florianópolis. Além disso, a organização de um momento de apreciação, debate, reflexão e criação conjunta à família foi, também, um dos propósitos que contribuíram para a efetivação deste projeto.

Uma das famílias participantes salientou que nunca tivera a oportunidade de visitar um museu em família, sobretudo com uma mediação elaborada especialmente a eles, pontuando que sentem falta de projetos culturais na cidade que incentivem os pais que têm filhos com deficiência a investirem nesse tipo de atividade.

Pôde-se perceber que a expectativa da mãe, em especial, era envolver seu filho em programas como este, com a família, porque através da escola invariavelmente isso já acontece. O que mais sobressaiu nessa experiência foi o fato de que todos os integrantes da família participaram muito, visto que se presumia que o filho com deficiência seria o foco, justamente por necessitar um diálogo diferenciado. No entanto, foi um momento de experimentação, curiosidade e troca para todos, incluindo a equipe, o que reafirma a ideia de experiência proposta por Dewey (1974), culminando na relação entre público, obra e mediador e os processos de criação de significados desencadeados entre esses.

A inserção deste programa piloto reafirmou que esse tipo de iniciativa funciona e é importante para todas as partes envolvidas: família, mediadores e museu. Porém, ações como essa estão ainda distantes de ser prioridade às instituições, porque demandam medidas e recursos que nem sempre são idealizados por essa.

\section{Família, acessibilidade e Inclusão nos espaços expositivos}

Os limites e as possibilidades na integração social de pessoas com deficiência estão vinculados mais ao meio social em que se encontram do que com as especificidades da deficiência em si. As oportunidades de desenvolvimento da autonomia, de individualidade, acesso à arte, cultura e outros - os quais fazem parte do processo de humanização - parecem ser oferecidos de forma desigual.

Do ponto de vista dos aspectos sociais, a arte é um instrumento de inserção e inclusão social, sendo uma ferramenta para modificar e transformar com qualidade a vida das pessoas com deficiência. Contudo, existe uma preocupação em considerar a arte por 
este ângulo, como um instrumento, algo isolado, descontextualizado, principalmente no caso dos que são rotulados como limitados, descaracterizando-a. Bueno (2002, p. 88-89) defende que:

A Arte é um elemento imprescindível para o desenvolvimento do ser humano social, cultural, psicológico, político e histórico. É fundamental considerá-la não como "instrumento de resgate da cidadania", mas sim um instrumento de exercício da cidadania.

Sendo assim, a arte no âmbito da Inclusão deve ser entendida não como uma atividade isolada, neutra, mas como conhecimento, relacionada aos processos que envolvem a cognição, o pensamento, as articulações, os significados, as associações, as relações, as comparações, as abstrações, enfim, tudo o que conduza à atitude de construção de conhecimento.

O conhecimento em arte deve acontecer na esfera escolar, pois é domínio do professor o estímulo dos processos que abarcam os saberes na disciplina. Porém, a formação cultural e artística de um indivíduo não se encerra na escola. A participação da família nesse aspecto é essencial para entender que, além da escola e das considerações correntes acerca da problemática da formação docente, é significativo o desempenho da criança fora desse contexto, que é vivência familiar.

Há autores que abordam a transmissão cultural por diferentes perspectivas, acentuando a importância da família e da escola. Invariavelmente ambas as instituições participam desse processo. Tourinho (2004) interroga-se sobre "onde" e "como" oferecer uma real oportunidade de aprendizagem em arte destacando que:

Muitos outros lugares, além da escola, podem ensinar arte, ciências ou geografia. Mas, enquanto a escola existir, legitimando, credenciando e discriminando as pessoas, no melhor e no pior dos sentidos, sua responsabilidade inclui, mas vai muito além do divertimento, do lazer e da criação. Estudos de público sobre a freqüência a museus, teatros e concertos, mostram que o nível educacional é o mais poderoso indicador de participação nessas atividades. (TOURINHO, 2004, p. 107). 
Não há como despolitizar a questão, pois existe desigualdade nas formas de distribuição e consumo de bens culturais, tanto dentro, quanto fora da escola. Talvez porque, segundo a autora supracitada, a própria escola sustente essa desigualdade, oferecendo privilégios àqueles que sabem ou fazem arte. Entretanto, saber e fazer são concepções ligadas à experiência humana, decorrentes de práticas vivenciadas no social - na coletividade - alicerçados na cultura de determinado contexto. Aqui, o papel da família é determinante na continuidade dessa ação, quando ela existe, iniciada na escola. A arte é fundamental à formação de crianças e jovens, e não se encerra na educação escolar, pois implica, além das práticas pedagógicas, o contexto que o indivíduo vivencia, suas atividades para além desta.

Os museus integram uma parcela essencial da vivência da arte fora da escola e, mesmo que frequentemente, vinculados a essa. Grande parte do público infanto/juvenil que vai ao museu é proveniente de saídas de estudos elaboradas pelas escolas. Quando se trata de pessoas com deficiência, a frequência a museus por parte da família é significativamente inferior, se comparada em relação à escola.

A pesquisa com as famílias reafirma esse dado, indicando que o ingresso a espaços culturais não é prioridade para elas, ainda que reconheçam a importância. As famílias sabem qual a relevância em inserir programações culturais e artísticas em sua vivência, mas ainda assim não efetivam essas ações. Bourdieu (2003, p.69) considera que "[...] nada é mais acessível do que os museus e que os obstáculos econômicos", salientando que são excluídos apenas aqueles que se excluem, fato exposto através do depoimento de algumas mães, as quais relataram que existem opções culturais, mas que a não frequência se dá em virtude da falta de hábito.

Bourdieu (1998; 2003) concebe o indivíduo a partir de seu meio social, configurado através de seus gostos, aptidões, preferências, posturas, aspirações, entre outros elementos socialmente constituídos. O autor enfatiza o capital cultural, em sua pesquisa nos museus da Europa, sugerindo que as famílias de elites investem mais em arte e cultura do que nos demais meios sociais. "A freqüência dos museus - que aumenta consideravelmente à medida que o nível de instrução é mais elevado corresponde a um modo de ser, quase exclusivo, das classes cultas." (BOURDIEU; DARBEL, 2003, p. 37). Através dos depoimentos das entrevistadas, constatou-se que a herança cultural discutida por Bourdieu (1998; 2003; 2007) pode ser validada no contexto pesquisado, porém, não se relaciona estritamente com a questão de classe social, debatida por ele. Isso porque a herança cultural não é propagada 
osmoticamente, como aponta o autor, mas depende de um trabalho ativo realizado pelos pais e também pelos filhos, podendo ter êxito ou não, contrariando a noção de herdeiro passivo, que recebe uma bagagem familiar privilegiada.

Os critérios são relativos e independem da classe social, a exemplo da pesquisa realizada, na qual se constatou que uma das famílias que viveu na Europa ${ }^{1}$ por muitos anos teve pouco contato com arte, ao passo que outra, na mesma situação, retornou ao Brasil com uma bagagem cultural fortemente enraizada no que foi experienciado lá fora. Outra família, do mesmo estrato social que as recém citadas, demonstrou não possuir hábito em investir em cultura e arte, o que não leva a crer que o investimento artístico é determinado apenas pela classe social, mas também por meio de outros fatores mais ou menos independentes em relação à divisão de classes, como a trajetória ascendente do grupo familiar, o nível educacional, o meio urbano, e, em muitos casos, como a postura mais ou menos conservadora e religiosa de cada família.

\section{O que dizem as mães sobre arte e acessibilidade}

As famílias pesquisadas foram organizadas em cinco grupos. Em todos os casos, foram as mães, e não os pais, que se dispuseram a conceder entrevistas, e para preservar suas identidades, receberam os seguintes nomes: Joana, Alice, Clara, Luiza e Rita, na ordem em que foram realizadas as entrevistas.

Inicialmente, as mães foram questionadas sobre o conceito que têm acerca da arte, e as respostas, no geral, caracterizaram-na como um "fazer". Isso porque no caso dessas mães, a arte é fundamental para o desenvolvimento motor da deficiência do filho, ou seja, é tratada como suporte, não como ferramenta de conhecimento.

Falar sobre arte? O que que a gente faz sobre...Em casa, assim, até pra estimular a coordenação motora, desde criança a gente faz várias, assim, por exemplo, numa mesa,... brincadeiras, desenhos com farinha, onde movimenta os braços, pra fazer movimento e daí forma um sol, forma um anjo, forma alguns desenhos. Seria uma forma de arte. [...] Eles não conseguem sentar, não conseguem andar e tem bastante dificuldade em mexer os braços, não conseguem escrever, né. Então a gente auxilia sempre na construção dos

\footnotetext{
${ }^{1}$ A primeira família morou na Espanha, e a segunda, na Inglaterra.
} 
movimentos deles, né, por exemplo, fazer com que eles segurem um pincel, eles façam uma pintura, por exemplo, né, eles já pintaram quadros, eles brincaram de massinha quando eram na idade né, hoje já não é mais idade de brincar de massinha. Então, na idade escolar, é este tipo de atividade: pintura, é...trabalhos com tinta, recortes.

(04 - Luiza)

Pareyson (1989) conceitua a arte através de três pilares: a arte como fazer, como conhecer ou como exprimir. Na concepção do autor, destaca-se o pensamento sobre arte em sua amplitude, não de forma isolada, pois não se restringe ao fazer nem tampouco à expressão e/ou ao conhecer, e sim a relação e a interação entre o fazer, o exprimir e o conhecer, o que não deixa de ser uma analogia à arte na educação, visto que o ensino de Arte é permeado por essas relações, o que elucida os princípios conceituados pelo autor aos debates sobre o assunto.

Neste sentido, o depoimento de Luiza evidencia o conceito de arte como um "fazer", sem a preocupação em distinguir ou pensar sobre as diferenças entre a arte propriamente dita e o ofício do artesão. Isso não resume afirmar que os trabalhos realizados por essa família não se vinculam à criação e à expressão. No entanto, além do fazer e da expressão que se inserem do campo da arte pontuados pelo autor citado, o conhecer, que concebe a arte através da cognição, interpretando o aspecto executivo como secundário, acaba ficando em segundo plano por ser algo de maior complexidade.

Nota-se a formação artística caracterizada a um fim mais específico, que é o auxílio ao desenvolvimento da coordenação motora. Relacionar a arte como terapia, ou como expressão, atividade que auxilia ao desenvolvimento, nesse caso, motor, é bastante comum às pessoas com deficiência, porque o histórico do ensino de Arte foi influenciado pelas concepções de livre expressão, estimulando a liberdade de criação, o "espontaneísmo".

A dicotomia entre essas reflexões reverberaram novas práticas e reformulações nas teorias. Bueno (2002) considera que uma das razões por qual a arte na área da Educação Especial e Educação Inclusiva terem, ainda hoje, concepções relacionadas à valorização da arte como expressão e da liberdade criadora, está enraizada nas décadas de 60 a 80, em que a tendência era seguir os padrões da Escola Nova, onde 
se concebia os pressupostos da Educação Especial. Contudo, a fala da mãe Luiza a respeito de sua prática cotidiana com arte não pode ser julgada de forma maniqueísta, pois essa mãe conduz da melhor forma a formação artística dos filhos, e àquilo que não the compete, como, por exemplo, as informações sobre determinado artista e contextos artísticos, bem como o processo de fornecer informações específicas sobre arte fica em segundo plano. Isso é tarefa das instituições, dos professores da disciplina, realizar essa mediação.

As falas das mães indicaram que as crianças costumam frequentar museus, espaços expositivos e demais atividades culturais por via da escola, atitude que fornece subsídios essenciais para a formação cultural da criança, segundo alguns depoimentos.

A escola organiza passeios bastante interessantes, né. Tanto de ir ao cinema, quanto de visitar um museu, O Victor Meirelles, a casa rosada, é, eles já fizeram, por exemplo, reconhecimento cultural, fazer volta à ilha, conhecer todas as praias da ilha, visitar o ribeirão da ilha, a igreja de Santo Antônio, o artesanato da ilha, o que é a rendeira, o pescador, visitar uma vila de pescadores...todas essas atividades são introduzidas tanto pela escola. A gente já fez arte culinária, de trazer uma pessoa pra ensinar culinária, eles já fazem um desenho, colocam cobertura e tal e depois comem. Na escola, por exemplo, eles já foram visitar o ateliê do Luciano Martins, estudaram a vida do Van Gogh, reproduziram um quadro do Van Gogh e depois reproduziram um quadro do Luciano, pintaram junto com o Luciano um quadro, então, acho que assim, em relação à arte pintada é essa, a arte música, é, eles já participaram de coral, na escola eles têm aula de música, eles têm aula de flauta, só se apresentam com flauta, conhecem outros instrumentos, constroem, aqui, no caso na E.A ${ }^{2}$, constroem instrumentos com material reciclável, fazem chocalhinhos, fazem apresentações. A inserção da arte é bem importante, assim.

(04- Luiza)

A escola é muito focada em arte naquilo que tá acontecendo na cidade, então eles foram passear, eles foram ver os monumentos da

\footnotetext{
${ }^{2}$ Abreviação do nome da escola que esta mãe possui. A escola em que os filhos estudam a qual ela se referiu quando detalhava as saídas de estudos é outra.
} 
cidade, que eu mesma ainda não $\mathrm{vi}^{3}$, tipo a figueira né, eles fizeram um passeio de ônibus. Eles foram em cinco pontos turísticos, ver canhão, o forte...

(05 - Rita)

Clara, a terceira mãe lembrou-se de um momento que marcou a vivência em arte para seu filho Daniel, que possui deficiência intelectual. Ele foi a uma exposição de arte organizada pela escola e relatou minuciosamente como foi a experiência, o que reafirma a importância da mediação educativa nos espaços expositivos, que pode instigar o aluno a retornar, pois sensibiliza, estimula a criticidade, o conhecimento, etc. Segundo Martins (2008a, p. 56) "uma mediação sempre será a articulação entre as histórias pessoais e coletivas dos aprendizes da Arte, enredada na teia sócio-histórico cultural da humanidade nessa área de conhecimento".

Quando ele foi à exposição ele contou, contou tudo o que ele fez lá, porque teve motivação, ele fica mais empolgado, ele também é bem hiperativo, então pra ele ficar preso só lá na sala, ele vai ficando cansado, ele não vai rendendo, se há alguma coisa diferente onde ele possa gastar energia, ele rende mais, ele faz as coisas com mais empolgação. Todas as aulas que são diferentes ele gosta.

(03 - Clara)

O questionamento sobre a frequência que as famílias destinam a visitar museus, espaços expositivos e culturais indicou, na maioria dos casos, que elas não priorizam esse tipo de evento.

Joana, a primeira mãe entrevistada, relatou que sua família não tem costume de ir ao museu, frente às atribulações de sua vida, comentando que apesar de nunca ter levado o Júlio, que tem Síndrome de Down, a um espaço expositivo, ele costuma ir a algumas saídas de estudos com o colégio, que contemplam o contato com arte.

\footnotetext{
${ }^{3}$ Alice está recentemente morando na cidade, por isso comenta que ainda não explorou todos os lugares e desconhece até mesmo alguns pontos turísticos.
} 
Museu eu nunca levei o Júlio, nem no teatro eu nunca levei o Júlio, porque nunca coincide com a minha vida...os horários... É, porque no caso você leva nas coisas assim básicas, assim, se tiver num shopping, uma coisa assim, mas não que você saia com aquele direcionamento: "eu estou saindo para ir ao teatro", né? Mas sim, você, né, vai sair quando aquilo tá no seu caminho, no seu passeio, mas não que você saiu com aquela intencionalidade de estar naquele lugar [...] Mas...se ele for pela escola, como ele já foi pelo CEI de São José, que sempre fazia passeios muito bons, de todas as espécies, né... todos os estilos, ele sempre curtiu; ele vai também pela escola ao teatrinho, que as vezes eles vão, né, fazer essas coisas, é legal, porque ele curte, ele vai né. Já muda aquele papel de mãe que começa a selecionar muito a vida, sabe, que é bom quando tá na escola, que na escola ele vai de qualquer maneira...só assinar, né.

(01 - Joana)

É pertinente destacar que através do depoimento de Joana o habitus, relacionado à cultura, será mais amplamente transmitido pela escola e pela cultura de massa do que através da família. Setton (2002) indica que o habitus é um produto das relações dialéticas entre uma exterioridade e uma interioridade, estruturado não somente pelos agentes tradicionais da educação, como família e escola, mas também é constituído pela cultura de massa, difundindo múltiplas informações e referências identitárias, o que caracteriza a socialização da contemporaneidade com base em múltiplos exemplos de referência.

A família 04 é a única, dentre as pesquisadas que possui o hábito de frequentar eventos artísticos e culturais, tanto na cidade quanto fora, e que além de acreditar na importância deste estímulo, procura manter sempre o contato com arte, seja em casa, fazendo coisas simples, atividades diárias, ou indo a locais que proporcionem experiências e vivências com arte e cultura. A mãe relatou que a frequência em museus se deu mais no período em que moraram na Europa, onde o estímulo era maior.

Eu...a gente sempre, assim ó: eu já morei fora do Brasil e a gente tem acho que mais contato a museu, assim, lá fora. Aqui a gente procura levar as crianças, a gente foi a Porto Alegre agora, levamos as crianças ao museu, a gente foi a São Paulo fazer um exame, levamos 
as crianças no museu, aqui em Florianópolis no $\mathrm{CIC}$, antes quando era mais disponível, assim, a gente ia, levava eles pra ver as obras de arte. Então é uma coisa que faz parte da nossa família; eu gosto, aprecio obras de arte, né. É, acho que assim, de tanto ver, conhecer, os quadros, tenho vários livros em casa, de vários pintores, de Miró, de Matisse, que eu gosto mais, assim... Picasso,... Eles sabem quem é o Van Gogh, conhecem o Luciano Martins, qual é o trabalho dele, então, assim, a gente tem bastante convivência assim com isso né.

(04 - Luiza)

A participação desta mãe na vida das crianças é notadamente efetiva, presente. Ela conversa com os filhos, instiga-os a relatarem suas aulas, o que acaba refletindo nas atividades extracurriculares.

Então a gente participa.......] Mas a gente sempre vai em alguma atividade que proporcione algum conhecimento assim, mais amplo da vida.

(04 - Luiza)

Os Parâmetros Curriculares Nacionais enfatizam a questão da arte como ferramenta de conhecimento, reiterando a fala da mãe acima. Segundo o PCN (2001), a arte envolve o conhecimento, que tem como base a experiência de fazer formas artísticas e tudo o que entra em jogo nessa criação, englobando várias ações, como a experiência de fruir formas artísticas, a experiência de refletir sobre a arte como objeto de conhecimento.

Rita também relata que a escola oportuniza muitas vivências em arte, incluindo pontos turísticos e outros roteiros que fornecem desde cedo contato com a história da cidade. Porém, quando este tipo de passeio não está atrelado à escola, é bastante raro de ocorrer. Um dos fatores pontuados é a questão da acessibilidade, à filha que possui paralisia cerebral e se locomove em cadeira de rodas.

Poxa, ir pro cinema até dá... Eu fui no teatro Pedro Ivo, e eu posso tá enganada, mas eu teria que carregar ela no colo, não achei fácil. [...] E a gente chegou lá, e com três crianças a gente tem que prestar 
atenção nelas. Mas eu acho que a acessibilidade ainda não é o... Ainda não tá legal.

(05 - Rita)

A entrevistada 04, Luiza, também salientou que o acesso ao teatro, ao museu e a demais locais que proporcionam contato com arte e cultura é demasiado difícil para o deslocamento com os filhos, que utilizam cadeira de rodas.

Então, realmente a gente participa. Na verdade o que nos limita a frequentar espaços expositivos é a acessibilidade, né. Que normalmente todos os museus aqui, por exemplo, o Cruz e Sousa não tem elevador, por exemplo. O Victor Meirelles tem uma escada na frente, não dá pra visitar o segundo andar. O Museu do Homem do Sambaqui, que eles foram visitar, não tem acesso, aí tem que entrar por trás, por não sei onde, passar por não sei o que, tem que ter três pessoas pra carregar cadeira, então realmente a limitação de visitação é a dificuldade de acesso.

(04 - Luiza)

Um dos aspectos primordiais na definição de uma política de acessibilidade é a readequação do espaço físico, além das escolhas das exposições a serem exibidas, considerando que os materiais devem ser adaptados para o recebimento de grupos que não têm o hábito de estar dentro da instituição.

Por muito tempo o campo da arte esteve limitado a um grupo que possuía o conhecimento específico para compreender, consumir e fomentar a produção artística. Os aspectos de papel social e divisão econômica foram utilizados como empecilhos que tornaram incompreensível a obra de arte ao conjunto da população. Porém, atualmente, em que o discurso e a lei são voltados à igualdade dos direitos, é essencial que ações sejam efetivadas para expandir a arte ao cotidiano das pessoas.

A pesquisada 04 aponta em seu depoimento que a oferta existe, mas falta interesse e, sobretudo, quase não há divulgação de eventos culturais. Ela ressalta que existem inúmeras atividades acontecendo, porém são pouco noticiadas e o interesse não é despertado ao público em geral, não faz parte da rotina da maioria das pessoas. 
Cabe destacar que esta mãe foi a que mais salientou a questão da acessibilidade em sua fala. É, também, a que mais frequenta espaços culturais e expositivos com sua família, tendo, portanto, subsídios para abordar este assunto, enquanto que as demais não discutiram sobre algo que não faz parte de suas vivências.

A gente foi a uma festa, sobre o Japão, lá na praça dos bombeiros, então, tinha muito pouca gente. Existem oportunidades, às vezes também as pessoas não valorizam. Teve um concerto de violino, teve um trabalho de dobradura que os japoneses fazem, de origami muito legal, teve o banho do Buda de chá, que faz parte da cultura deles, isso é só apenas um exemplo. Mas a gente vai em outras feiras, em outras festas, a gente participa bastante. [...] Então, assim, têm eventos sim, têm situações, mas a gente às vezes não se mobiliza pra ir. Já aconteceu uma vez, a gente fez um passeio aqui da E.A, pra visitar um museu, eu acho que foi a Casa Rosa, quando a gente chegou lá, tava fechado, porque tinha falecido uma pessoa, e naquele dia eles decidiram fechar o museu, sabe? [...] O que que a gente fez: passeamos na praça $X V$, vimos artesanato, fomos lá na alfândega, vimos todo o artesanato, aproveitamos o nosso dia, mas não foi o que a gente se propôs a ir, e foi contra a nossa vontade. Então essas situações assim que acontecem...isso eu acho provinciano, sabe, a forma como é lidada essa atenção. Não que não existe oferta. Eu tava vendo na semana passada no jornal, tá tendo uma...não sei o que que é, encontro de museus, uma coisa que tá tendo, várias exposições que estão rolando no Brasil todo e passam em vários museus, saiu uma notinha assim, deste tamanho sabe!

(04 - Luiza)

Além da pouca divulgação, a falta de incentivo e de oferta determina muitas vezes a pouca frequência das famílias a eventos culturais. Ademais, o museu ainda não possui estrutura para receber pessoas com deficiência, dado constatado em várias falas dessa mãe. A reestruturação dos espaços deve ser prioridade para a equalização de oportunidades a este público, para garantir o acesso que é direito de todos.

Porém, esta ação é apenas o ponto de partida; não resulta numa mudança repentina de um modo de vida que já está estabelecido. As famílias não vão se interessar instantaneamente por mediações culturais. Para isso, a equipe de um museu deve buscar criar vínculos ao público não iniciado em espaços expositivos, para que seja 
motivado a retornar. No momento em que houver a valorização de novas linhas de produção artística e essas serem incorporadas às curadorias, este público antes excluído, poderá criar o hábito de estar em contato com a arte e frequentar mais vezes museus e eventos culturais, ampliando seu repertório artístico e enriquecendo a vivência de toda a família no âmbito da arte.

\section{Considerações finais}

A inclusão de pessoas com deficiência em espaços expositivos é um desafio, no que diz respeito à acessibilidade, porque cada deficiência requer um projeto exclusivo que demanda pesquisa e elaboração, por parte das instituições. Para tanto, são necessárias mudanças culturais e institucionais, pois é necessária a adequação da instituição a fim de atender a esse público.

Ao longo do texto, observou-se que a acessibilidade não está completamente efetivada ao público com deficiência, o que, no entanto, não impede as famílias que já possuem o hábito de frequentar espaços expositivos e eventos culturais de estarem sempre dispostas a ir a esses lugares. O problema é a acessibilidade aos nãoiniciados, àqueles que não costumam visitar espaços culturais, distanciando-se mais desses. A experiência em desenvolver projetos no âmbito da família em museus é uma estratégia que possibilita trocas entre ambos, constituindo uma postura reflexiva, dialogal e construtiva entre família e museu.

É prudente afirmar que, já que o museu é um espaço de reflexão sobre a arte, a ação educativa deve ser uma referência para a sociedade, dando direito a todos à comunicação e participação no universo artístico, possibilitando ao público a oportunidade de ser espectador e participador do meio cultural contemporâneo.

O público de pessoas com deficiência faz parte de uma parcela que nem sempre teve acesso aos bens culturais com igualdade. A arte não é, nem foi acessível a todos na história da humanidade. Por muito tempo o campo da arte esteve limitado a um grupo que possuía o conhecimento específico para compreender, consumir e fomentar a produção artística.

O objeto de arte foi muitas vezes utilizado como ferramenta ideológica de dominação e símbolo de poder das classes dominantes, sobrepujando às pessoas com deficiência. 
A concepção de arte institucionalizada se refere àquela que pertence aos espaços consagrados à arte, tais como galerias, museus e espaços expositivos. Estas manifestações artísticas estão, em sua maioria, concentradas nos grandes centros, os quais nem sempre promovem acesso ao público em geral.

Não obstante, existem dificuldades em possibilitar às pessoas com deficiência experiências variadas no contexto da cultura, bem como a falta de material adaptado, programas de incentivo, curadorias, entre outros. No caso de ações que promovam a ida da família ao museu, a escassez de programas nesse âmbito são ainda maiores. Os dados da pesquisa mostraram que a acessibilidade é o empecilho que permeia as razões pelas quais as famílias não vão a espaços expositivos e culturais com seus filhos. No entanto, ficou claro através de depoimentos, especialmente os da entrevistada 04, que é preciso adquirir hábito em exercer esses passeios, pois, segundo ela, muitos locais acessíveis ficam vazios quando se trata de eventos culturais. Talvez por medo, insegurança e falta de informação, a família resguarde a criança com deficiência como estratégia de proteção.

O desenvolvimento da formação artística do filho com deficiência é condicionado a uma série de fatores relacionados ao hábito, à motivação e ao grau de importância que é dado à própria arte. Os agentes que operam esses fatores são, em primeiro lugar, a escola, que têm a função de desencadear esse processo; as instituições (museus, galerias, teatros, entre outras), que devem criar mecanismos que instiguem o público visitante a retornar a esses espaços; a família, que, consequentemente, ao ser incentivada pelos agentes anteriores, precisa se organizar e priorizar esse tipo de atividade na medida em que perceber sua importância.

Os museus de arte que pretendem ser acessíveis a toda a sociedade deverão ter conhecimento das políticas públicas que prevêem a inclusão de pessoas com deficiência, efetivando todos os recursos para atender a este público. É um processo longo, mas possível. É imprescindível mobilizar ações que seduzam as pessoas com deficiência e suas famílias à arte. 


\section{Referências Bibliográficas}

Convenção sobre o Direito das Pessoas com Deficiência: Protocolo Facultativo à Convenção sobre os Direitos das Pessoas com Deficiência. Brasília: Secretaria Especial dos Direitos Humanos, 2007.

BOURDIEU, P. A economia das trocas simbólicas. São Paulo: Perspectiva, 2007. . Futuro de classe e causalidade do provável. In: NOGUEIRA, M. A.; CATANI, A. (Org.). Escritos de educação. Petrópolis, RJ: Vozes, 1998. Leis da difusão cultural. In: BOURDIEU, P.; DARBEL, A. O amor pela arte: os museus de arte na Europa e seu público. São Paulo: Zouk, 2003.

BOURDIEU, P.; DARBEL, A. O amor pela arte: os museus de arte na Europa e seu público. São Paulo: Zouk, 2003.

BUENO, R. P. P. A arte na diferença: um estudo da relação da arte/conhecimento do deficiente mental. Piracicaba, SP, 2002, 218 p. Tese de Doutorado - Faculdade de Educação, Universidade Metodista de Piracicaba.

DEWEY, J. Tendo uma experiência. In: Arte como experiência - Os pensadores. São Paulo: Abril SA Cultural, 1974.

MARTINS, M. C. Conceitos e terminologia - Aquecendo uma transforma-ação: atitudes e valores no ensino de Arte. In: BARBOSA, A. M. (org.). Inquietações e mudanças no ensino da arte. São Paulo: Cortez, 2008a.

PARÂMETROS CURRICULARES NACIONAIS: arte / Ministério da Educação.Secretaria da Educação Fundamental. Brasília: A Secretaria, 2001.

PAREYSON, L. Os problemas da Estética. São Paulo: Martins Fontes, 1989.

SETTON, M. G. J. A teoria do habitus em Pierre Bourdieu: uma leitura contemporânea. Revista Brasileira de Educação, Maio/Jun/Jul/Ago 2002 No 20. Disponível em: <http:// www.anped.org. br/rbe/rbedigital/rbde20/ rbde20_06_maria _da_graca_jacinto_setton.pdf>. Acesso em: 17.12.2010.

TOURINHO, I. Educação Visual: pensando o currículo através de perguntas. In: MEDEIROS, Ana Beatriz de (org.). Arte em pesquisa: especificidades. Brasília - DF: Editora da Pós-Graduação em Arte da Universidade de Brasília, 2004. 